\title{
Cell-penetrating peptide-mediated transformation of large plasmid DNA into Escherichia coli
}

Md Monirul Islam, ${ }^{\ddagger}{ }^{\dagger}$ Masaki Odahara, ${ }^{\ddagger}$ Takeshi Yoshizumi, ${ }^{\ddagger}{ }^{\ddagger}$ Kazusato Oikawa, ${ }^{\ddagger}$ Mitsuhiro Kimura, ${ }^{\ddagger \dagger}$ Masayuki Su'etsugu, ${ }^{\S}$ Keiji Numata**

†Biomacromolecules Research Team, RIKEN Center for Sustainable Resource Science, 2-1 Hirosawa, Wako-shi, Saitama 351-0198, Japan

§Department of Life Science, College of Science, Rikkyo University, 3-34-1 Nishi-Ikebukuro, Toshima-ku, Tokyo, 171-8501, Japan.

* Correspondence should be addressed to K.N. (keiji.numata@riken.jp).

$\dagger$ Please see Present Addresses

KEYWORDS: cell-penetrating peptide, Escherichia coli, large-sized plasmid DNA, genetic material transformation 


\section{Materials and Methods}

\section{CPP Synthesis}

(KH) ${ }_{9}$-BP100 (amino acid sequence: KHKHKHKHKHKHKHKHKHKKLFKKILKYL-NH ${ }_{2}$, and theoretical $\mathrm{pI} / \mathrm{Mw}$ : 10.81/3809.71 $\mathrm{Da}$ ) were synthesized using standard 9fluorenylmethoxycarbonyl (Fmoc) solid phase peptide synthesis. ${ }^{1}$ The polypeptides were purified using high-performance liquid chromatography (HPLC) and the molecular weights were confirmed by matrix assisted laser desorption/ionization-time-of-flight (MALDI-TOF) mass spectrometry.

\section{Plasmid DNA extraction, purification and concentration measurement}

E. coli DH10B harboring pMSR227 (205 kb) plasmid were prepared according to a previous report. ${ }^{2}$ Those $E$. coli cells were cultured in LB-broth medium and further extracted using a NucleoBond ${ }^{\mathbb{B}}$ Xtra BAC kit (MACHEREY-NAGEL GmbH \& Co. KG, Germany) following the instruction from provider company. pMSR227 plasmid was purified by drop dialysis with 0.05 $\mu \mathrm{m}$ Millipore MF membrane filter (Merck Millipore, Burlington, MA) and recovered by ethanol precipitation. The integrity and purity of plasmid DNA (pDNA) were analyzed using $1.0 \%$ agarose gels for $16 \mathrm{~h}$ in in a CHEF Mapper or CHEF DRIll pulsed field gel box (BioRad Laboratories, Hercules, CA) in $0.5 \times \mathrm{TBE}$ at $25^{\circ} \mathrm{C}$ with a voltage gradient of $6 \mathrm{~V} / \mathrm{cm}$ and the switch interval ramped from 5 to $15 \mathrm{~s}$. DNA sizes were determined by comparison with the $\lambda$ ladder size markers of New England BioLabs (Ipswich, MA). At first, the pDNA concentration was determined by the analysis of DNA band intensity for at least 10 serial dilution of pDNA and DNA marker. Secondly, the pDNA concentration was determined using a NanoDrop Jasco UV-vis spectrophotometer (Jasco, Tokyo, Japan) at fixed wavelengths of $260 \mathrm{~nm}$. The purity of pDNA was compared by $260 / 280$ or $260 / 230$ absorbance standard ratio.

\section{Preparation of $E$. coli DH5 $\alpha$ chemical competent cells}

E. coli $\mathrm{DH} 5 \alpha$ chemical competent cells were prepared by the previously reported procedure with minor modifications to the protocol. ${ }^{3}$ Briefly, $5 \mathrm{~mL}$ fresh overnight culture was diluted into 100 LB growth medium. The cells were grown at $37^{\circ} \mathrm{C}$ with shaking at $200 \mathrm{rpm}$ to an $\mathrm{OD}_{600}$ of 0.7 (never higher than 0.8 , except where noted). The cells were harvested by spinning in a GSA rotor for $10 \mathrm{~min}$ at $5000 \mathrm{rpm}$ and re-suspended in $8 \mathrm{~mL}$ of $50 \mathrm{mM} \mathrm{CaCl}_{2}$. Spinning for $10 \mathrm{~min}$ at 5000 rpm collected cells at $4^{\circ} \mathrm{C}$. This washing and spinning procedure was then repeated, again using $8 \mathrm{~mL}$ of $50 \mathrm{mM} \mathrm{CaCl}_{2}$. After decanting the supernatant, cells were re-suspended in $4 \mathrm{~mL}$ of 50 $\mathrm{mM} \mathrm{CaCl} 2$ with $15 \%$ glycerol. The cells were incubated for $2 \mathrm{~h}$ on ice. The cells were aliquoted 
to microfuge tubes $(200 \mu \mathrm{L} /$ tube) and frozen quickly in a liquid nitrogen. The cells were stored until use at $-80{ }^{\circ} \mathrm{C}$.

\section{Preparation of $E$. coli DH5 $\alpha$ electro competent cells}

E. coli DH5 $\alpha$ electro competent cells were prepared by the procedure supplied with the electroporation device (BioRad Laboratories), with minor modifications to the protocol. ${ }^{3}$ A fresh overnight culture was diluted at 1:1000 for growth in $\mathrm{LB}$ (without $\mathrm{Mg}$ ion). The cells were grown at $37^{\circ} \mathrm{C}$ with shaking at $200 \mathrm{rpm}$ to an OD600 of 0.7 (never higher than 0.8 , except where noted). The cells were harvested by spinning in a GSA rotor for $10 \mathrm{~min}$ at $5000 \mathrm{rpm}$ and resuspended in a volume of cold $15 \%$ sterile glycerol equal to the original culture volume. The cells were harvested by spinning for $10 \mathrm{~min}$ at $5000 \mathrm{rpm}$ at $4{ }^{\circ} \mathrm{C}$. This washing and spinning procedure was then repeated, again using a volume of $15 \%$ glycerol equal to the original culture volume. After decanting the supernatant, the cells were suspended in the volume of glycerol remaining in the centrifuge bottles $(40 \mathrm{~mL})$ and spun for $10 \mathrm{~min}$ at $7000 \mathrm{rpm}$ with an GSA rotor. After decanting the supernatant, the cells were resuspended in $10 \%$ glycerol. The cells were aliquoted to microfuge tubes $(200 \mu \mathrm{L} /$ tube $)$ and frozen quickly in a dry ice-ethanol bath. The competent cells were stored until use at $-80^{\circ} \mathrm{C}$.

\section{The comparison of transformation efficiency between chemical and electro competent cells}

The initial transformation of chemical competent cells or electro competent cells were evaluated with pUC19 (2686 bp) of different concentrations. The transformation efficiency of large pDNA, pMSR227 $(205 \mathrm{~kb})$, was calculated by following eq. 1. After getting eight independent results, transformation efficiencies were compared between chemical competent cells and electro competent cells.

Transformation efficiency by colony forming unit (CFU) $=\frac{\text { Number of colonies on Plate }(\mathrm{df})}{\text { Amount of DNA plated }(\mathrm{ng})} \times$ $1000 \mathrm{ng} / \mu \mathrm{g}$ (eq. 1$)$

\section{Electroporation}

Electroporation was carried out using either a BioRad Gene Pulser II (BioRad Laboratories). Electroporation cuvettes with a $0.1 \mathrm{~cm}$ gap were placed on ice to chill. Electrocompetent cells were thawed and $50 \mu \mathrm{L}$ of the cells were added to microfuge tubes placed on ice. After $1 \mu \mathrm{L}$ DNA was added, the DNA and cells were transferred to the cuvette. Electroporation conditions 
were $100 \Omega 1.8 \mathrm{kV}$ and $25 \mu \mathrm{F}$, except where otherwise noted. Electroporation were performed in triplicate. After electroporation, $0.5 \mathrm{~mL}$ LB-broth was immediately added to the cuvette and the contents were then transferred to sterile glass culture tubes for 45 min growth with shaking at $37{ }^{\circ} \mathrm{C}$. For each electroporation $100 \mu \mathrm{L}$ of cells, each in triplicate, were spread on LB plates containing $50 \mu \mathrm{g} / \mathrm{mL}$ kanamycin. The plates were incubated for over $12 \mathrm{~h}$ at $37{ }^{\circ} \mathrm{C}$ for the growth of colonies.

\section{Characterization of Ionic Complexes of peptide and pDNA}

pMSR227 (205 kb, encodes a mCherry fluorescence protein) were mixed with (KH) $)_{9}-\mathrm{BP} 100$ to make a complex at various N/P ratios $(0.05,0.1,0.5,1,2$ and 5). Here, N/P ratio refers to the number of amine groups from the peptide/the number of phosphate groups from pDNA. To prepare the peptide-pDNA complexes, $0.5 \mathrm{~g} / \mathrm{L}$ of peptides were mixed with pDNA solution (approximately $1.0 \mathrm{mg} / \mathrm{mL}$ ) at various $\mathrm{N} / \mathrm{P}$ ratios $(0.05,0.1,0.5,1,2$ and 5$)$ at $25{ }^{\circ} \mathrm{C}$. The total amount of pDNA was 1 or $2 \mu \mathrm{g}$. The complexes were characterized immediately after mixing by a zeta potentiometer (Zetasizer Nano-ZS; Malvern Instruments, Ltd., Worcestershire, UK). The solution containing the complexes was diluted to a final volume of $800 \mu \mathrm{L}$ using ultrapure water (Milli-Q) and used for zeta potential and size measurements. Zeta potential and zeta deviation of samples were measured three times by a zeta potentiometer, and the average data were obtained using Zetasizer software ver. 6.20 (Malvern Instruments, Ltd.). Dynamic light scattering (DLS) was performed to determine the hydrodynamic diameter, and the polydispersity index (PDI) was determined with a zeta nanosizer (Zetasizer software ver 6.20) using a $633 \mathrm{~nm} \mathrm{He}-\mathrm{Ne}$ laser at $25^{\circ} \mathrm{C}$ with a backscatter detection angle of $173^{\circ}$. Atomic force microscope (AFM, Hitachi Hightechnologies, Tokyo, Japan) was measured at different N/P ratio to observe the peptide-pDNA complexes. The complex solution was cast on cleaved mica and observed in air at $25^{\circ} \mathrm{C}$ using a silicon cantilever with a spring constant of $1.3 \mathrm{~N} / \mathrm{m}$ in tapping mode AFM. The calibration of the cantilever tip-convolution effect was performed to obtain the true dimensions of the pDNA complexes using the methods reported previously. ${ }^{4}$ For gel retardation assay, $40 \mu \mathrm{L}$ of each sample at different N/P ratio containing 1.0 or $2.0 \mu \mathrm{g}$ of pDNA was mixed with loading buffer and analyzed on $1 \%$ agarose gel (TAE buffer, $100 \mathrm{~V}, 30 \mathrm{~min}$ ) and stained with ethidium bromide.

\section{CPP-pDNA complex formation for transformation}

$(\mathrm{KH})_{9}-\mathrm{BP} 100$ and pDNA complexes were prepared by adding of $2.5 \mathrm{mg} / \mathrm{mL}$ pMSR227 to increasing volumes of each CPP at various N/P ratios $(0.05,0.1,0.5,1,2$ and 5) and autoclaved Milli-Q water to obtain a final volume of $100 \mu \mathrm{L}$. The solution was thoroughly mixed (by repeated pipetting) and allowed to stabilize for $30 \mathrm{~min}$ at $25^{\circ} \mathrm{C}$. The complexes were mixed with E. coli $\mathrm{DH} 5 \alpha$ by repeated pipetting and allowed to transfect the membrane for $30 \mathrm{~min}$ at $25^{\circ} \mathrm{C}$. 
Then, $1 \mathrm{~mL}$ LB-broth was added to the tube and transferred to incubator at $37{ }^{\circ} \mathrm{C}$ for $1 \mathrm{~h}$ to release the pDNA in cytoplasm and degrade the peptide. Then, the tubes were centrifuged for 1 min at $8000 \mathrm{rpm}$ and plated approximately $100 \mu \mathrm{L}$ of LB-broth.

\section{Quantification for transformation efficiency: Colony forming units (CFUs)}

After overnight incubation, photos of the agar plates are taken with a Nikon digital camera (Nikon, Tokyo, Japan). Colony forming units (CFUs) are counted by ImageJ (NIH, Bethesda, $\mathrm{MD})$ and calculated by eq. 1 . Here, transformation efficiency is defined as the CFU in ampicillin or kanamycin containing LB agar plates per 1.0 or $2.0 \mu \mathrm{g}$ DNA. Transformation efficiency (\%) was calculated by eq. 2 .

Transformation efficiency $(\%)=\frac{[\mathrm{CFU}] / \mu \mathrm{g} \text { DNA }}{\text { Total number of cells plated }(\mathrm{ng})} \times 100$

\section{Evaluation of extracted pDNA with restriction endonuclease}

CPP-mediated transformed pDNA were extracted by a NucleoBond ${ }^{\circledR}$ Xtra BAC kit (MACHEREY-NAGEL GmbH \& Co. KG, Germany) and finally dissolve in TE. Extracted pDNA were run for $18 \mathrm{~h}$ in $1 \%$ agarose gels (SeaKem LE; FMC BioProducts, Rockland, ME) in a CHEF Mapper or CHEF DRIll pulsed field gel box (BioRad Laboratories) in $0.5 \mathrm{x}$ TBE at $14 \mathrm{WC}$ with a voltage gradient of $6 \mathrm{~V} / \mathrm{cm}$ and the switch interval ramped from 5 to $15 \mathrm{~s}$. Miniprepped pDNA $(5 \mu \mathrm{g})$ was digested in a volume of $20 \mu \mathrm{L}$ for 3-4 h using XhoI restriction endonuclease (New England BioLabs). DNA sizes were determined by comparison with positive control and $\lambda$ ladder size markers of New England BioLabs.

\section{CLSM experiments to observe the $m$ Cherry expression}

The expression of $m$ Cherry reporter gene was evaluated using E. coli DH10B harboring pMSR227 as a positive control and pMSR 227 transformed E. coli DH5 $\alpha$, respectively. At first, a blank experiment was conducted with $10^{6}$ cells $/ \mu \mathrm{L}$ E. coli DH5 $\alpha$ and confirmed the single layer of the sample. The mCherry expression was visualized by a LSM800 (Carl Zeiss, Oberkochen, Germany) with $63 \mathrm{x}$ oil immersion objective lens using $587 \mathrm{~nm}$ excitation and $610 \mathrm{~nm}$ emission wavelengths. The entire images were recorded digitally in a $2048 \times 2048$ pixel formats. E. coli DH5 $\alpha$ without transformation was used as a negative control. 


\section{Statistical Analysis.}

Statistical differences in transfection efficiency were determined by an unpaired t-test with a two-tailed distribution, and differences were considered statistically significant at $p<0.05$ by GraphPad Prism 7.0c for Macintosh. The data in the transfection efficiency experiments are expressed as means \pm standard deviation $(n=8)$.

\section{Results}

\section{Characterization of the complexes}

Based on the DLS results (Table S1 and Figure S1), the average hydrodynamic diameters of complexes of $(\mathrm{KH})_{9}$-BP100 decreased with increasing N/P ratios from 0.01 to 5 . The pDNA complexes prepared at $\mathrm{N} / \mathrm{P}$ ratios of more than 0.1 were successfully formed based on the average hydrodynamic diameters. On the other hand, the pDNA complexes at N/P 0.01 exhibited bimodal distributions, suggesting heterogeneous formation of the pDNA complexes. The diameters of the complexes prepared at N/P ratios of 0.5 and 1 were approximately $300 \mathrm{~nm}$ for $200 \mathrm{~kb}$ pDNA, whereas the complexes at N/P ratios of 2 and 5 had diameters of around $250 \mathrm{~nm}$. The zeta potential for pDNA complexes of $(\mathrm{KH})_{9}-\mathrm{BP} 100$ showed negative values at N/P ratios of 0.05 and 0.5 but increased to positive values at N/P ratios ranging from 1 to 5 (Figure S1). This saturation of the zeta potentials indicated that the peptides covered the surface of the pDNA complexes at an N/P ratio of 5 .

Agarose gel electrophoresis was also conducted to characterize the ionic interaction and electrolytic stabilities of the complexes (Figure S2). Larger migration of naked pDNA in the agarose gel denotes that the ionic complexes are less stable, which also means that the interaction between the peptides and pDNA are weaker. The complexes of $(\mathrm{KH})_{9}-\mathrm{BP} 100$ prepared at N/P ratios from 0.05 to 2 showed migration of pDNA across the gel similar to that seen for the free pDNA. The amount of migrated pDNA decreased with an increase in N/P ratio, indicating that more stable complexes of pDNA and fusion peptides formed at higher N/P ratios. 
Table S1. Characterization of the pDNA-CPP complex size and polydispersity index (PDI) at different $\mathrm{N} / \mathrm{P}$ ratios ranging from 0.05 to 5 .

\begin{tabular}{lll}
\hline N / P ratio & \multicolumn{2}{l}{ pMSR227 (205 kb) } \\
\hline & Size, nm & PDI \\
\hline 0.05 & $515 \pm 24.0$ & $0.55 \pm 0.20$ \\
\hline 0.1 & $490 \pm 35.3$ & $0.45 \pm 0.16$ \\
\hline 0.5 & $315 \pm 4.4$ & $0.31 \pm 0.01$ \\
\hline 1 & $298 \pm 20.8$ & $0.25 \pm 0.06$ \\
\hline 2 & $265 \pm 7.5$ & $0.16 \pm 0.04$ \\
\hline 5 & $236 \pm 10.5$ & $0.10 \pm 0.1$ \\
\hline
\end{tabular}




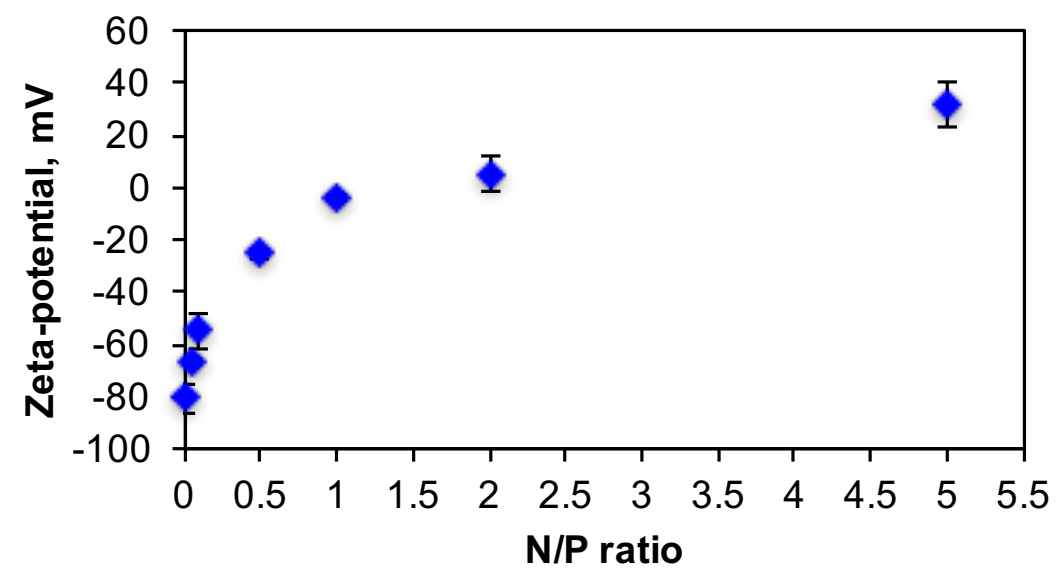

Figure S1. The zeta-potential of the pDNA and $(\mathrm{KH})_{9}$-BP100 complexes prepared at different $\mathrm{N} / \mathrm{P}$ ratios ranging from 0.05 to 5 .

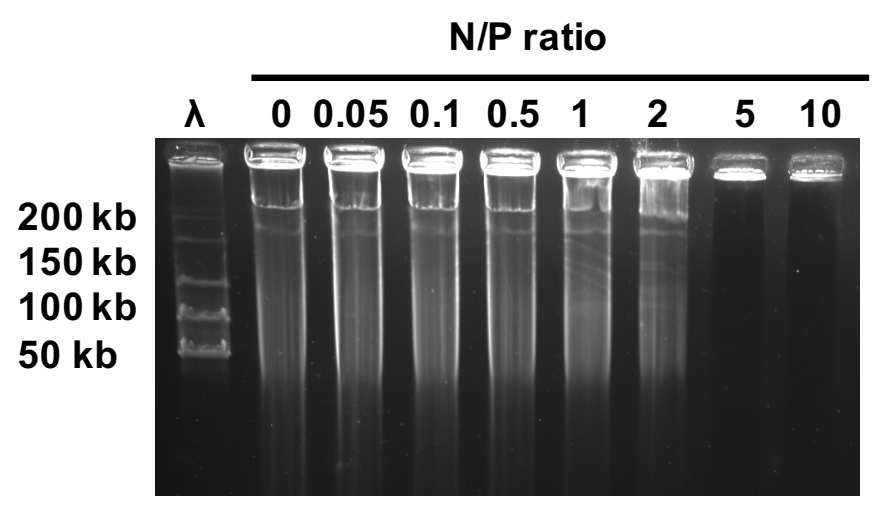

Figure S2. Gel retardation assay of the $205 \mathrm{~kb}$ pDNA complexes of $(\mathrm{KH})_{9}-\mathrm{BP} 100$ prepared at different $\mathrm{N} / \mathrm{P}$ ratios. 

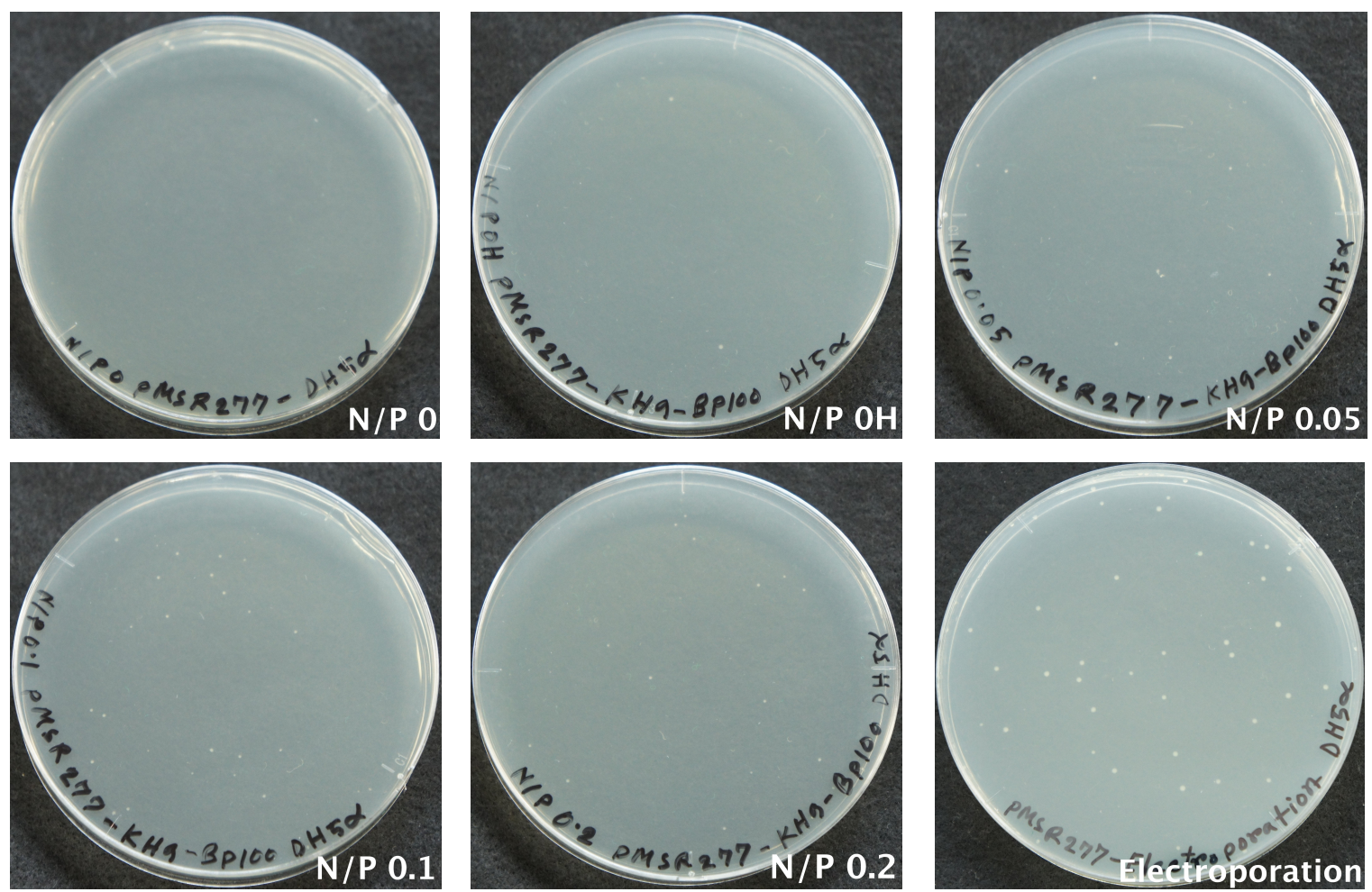

Figure S3. Comparison of transfection efficiencies of CPP-mediated pDNA delivery to E. coli $\mathrm{DH} 5 \alpha$. Colony forming units (CFU) used to quantify transformation efficiencies after CPPmediated transformation or electroporation to E. coli $\mathrm{DH} 5 \alpha$. 
a

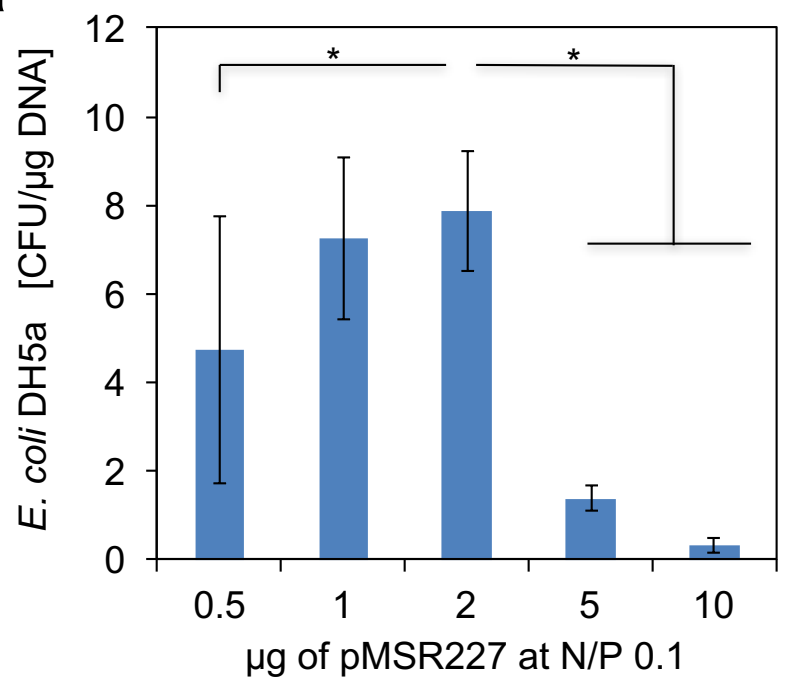

b

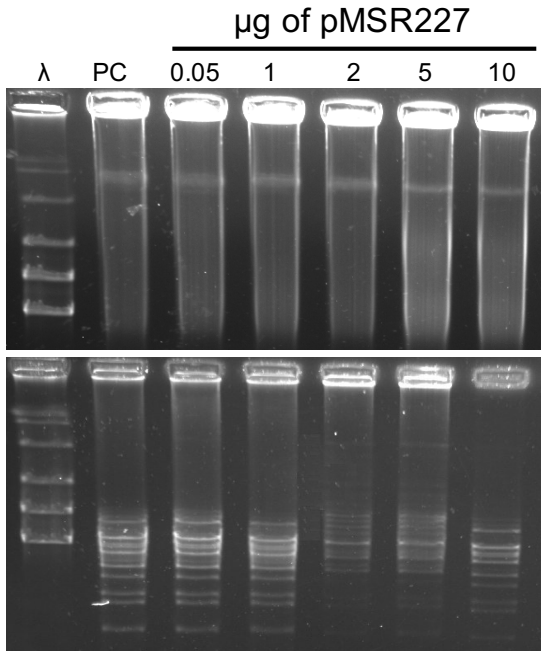

Figure S4. Comparison of transfection efficiencies of CPP-mediated pDNA delivery to E. coli DH5 $\alpha$. a) the comparison of CFU from electroporation, heat-shock and CPP-mediated $205 \mathrm{~kb}$ transformation at different N/P ratio. b) Electrophoretic mobility of intact $205 \mathrm{~kb}$ DNA extracted from CPP-mediated transformation by mini-prep (upper panel) and it digested by XhoI restriction endonuclease at the position of $52 \mathrm{~kb}, 43 \mathrm{~kb}, 38 \mathrm{~kb}, 29 \mathrm{~kb}, 14.4 \mathrm{~kb}, 10.4 \mathrm{~kb}, 7.5 \mathrm{~kb} 6.4$ $\mathrm{kb}$ and $4.4 \mathrm{~kb}$ (lower panel). Each data point represents the average of the eight separate trials (n $=8$ ). Error bar measured by Standard deviation, *t-test and $p<0.01$. " $\lambda$ ” denotes $\lambda$-DNA marker and "PC" denotes positive control. 


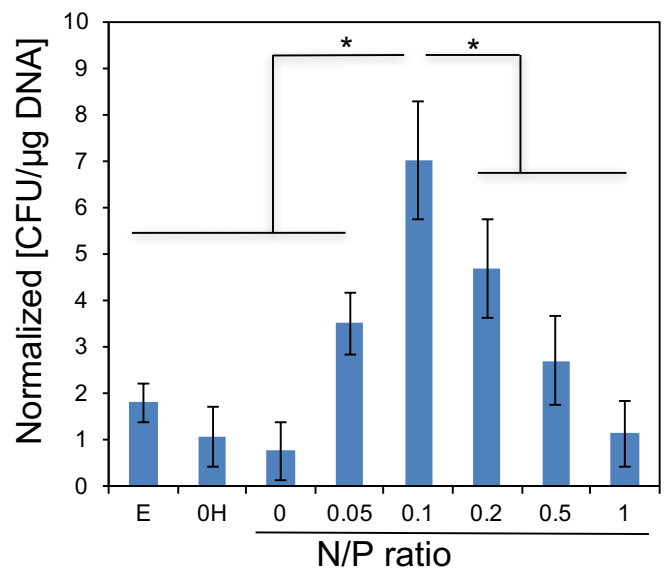

Figure S5. Normalized efficiency: Transformation efficiencies of CPP-mediated pDNA delivery to $E$. coli $\mathrm{DH} 5 \alpha$ were normalized by each competency of the $E$. coli $\mathrm{DH} 5 \alpha$ competent cells, because of the significant difference in competency between chemical and electro competent cells. The number of $E$. coli DH5 $\alpha$ cells in the electro competent cell was higher than that of the chemical competent cell, which was caused of the different competency. The comparison of CFU among electroporation, heat-shock and CPP-mediated $205 \mathrm{~kb}$ pDNA transformation at different N/P ratio. "E" denotes electroporation. "N/P0" denotes only pDNA, " $0 \mathrm{H}$ " denotes heat shock, Each data point represents the average of the eight separate trials (n $=8$ ), Error bar measured by Standard deviation, *t-test and $\mathrm{p}<0.01$; “ $\lambda$ ” denotes $\lambda$-DNA marker and "PC" denotes positive control. See the text for details. 


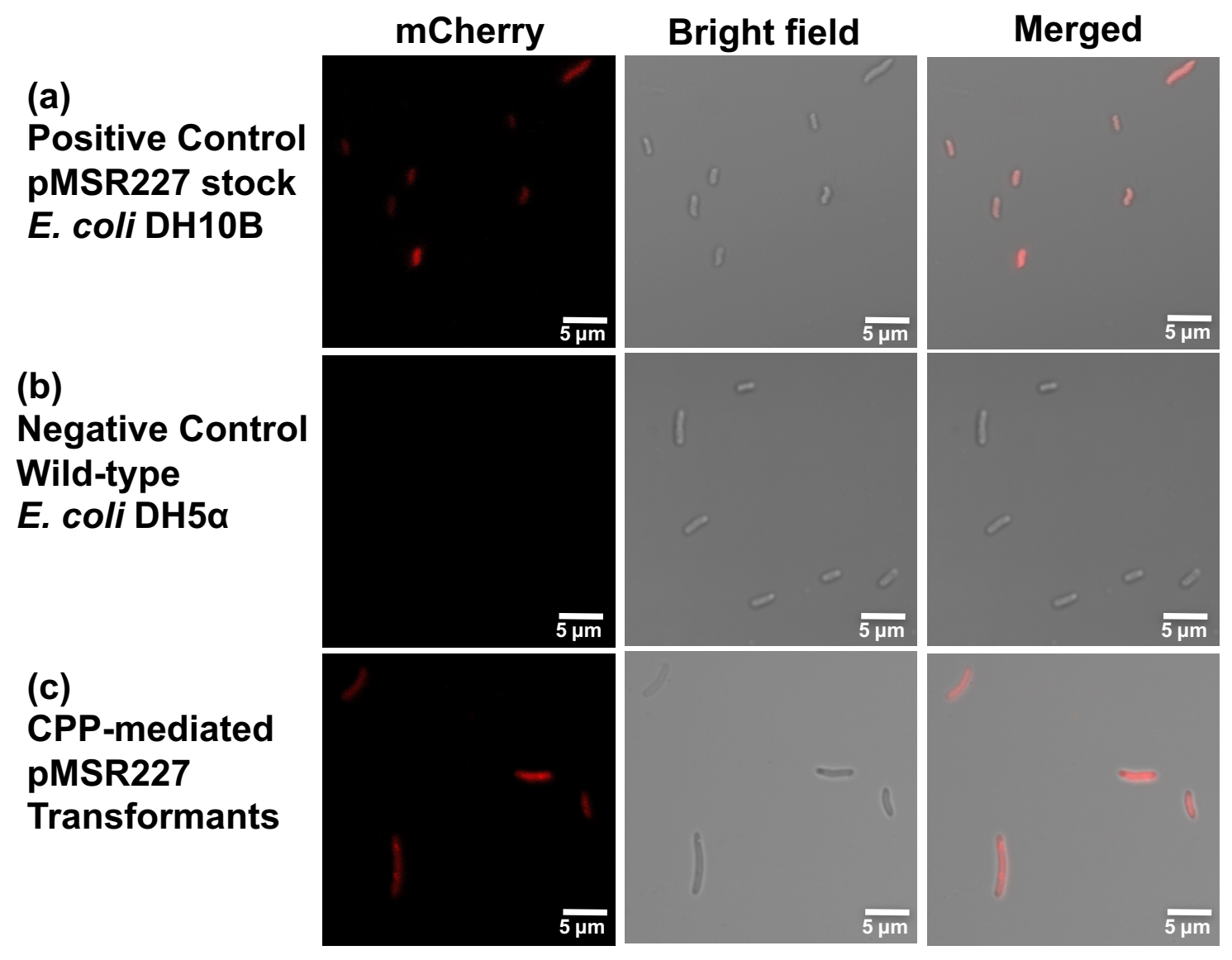

Figure S6. CLSM images of the expression of $m$ Cherry in E. coli DH5 $\alpha$. Overlay images of mCherry and DIC images. (a) As a positive control, transformant E. coli DH10B harboring pMSR227 encoding $m$ Cherry. This was prepared in the previous study. ${ }^{2}$ (b) Wild-type E. coli DH5 $\alpha$ as a negative control. (c) CPP-mediated transformant E. coli DH5 $\alpha$ harboring pMSR227 encoding $m$ Cherry. 
References

(1) Fields, G. B., and Noble, R. L. (1990) Solid phase peptide synthesis utilizing 9fluorenylmethoxycarbonyl amino acids, Int. J. Peptide Protein Res. 35, 161-214.

(2) Su'etsugu, M., Takada, H., Katayama, T., and Tsujimoto, H. (2017) Exponential propagation of large circular DNA by reconstitution of a chromosome-replication cycle, Nucl. Acids Res. 45, 11525-11534.

(3) Dower, W. J., Miller, J. F., and Ragsdale, C. W. (1988) High efficiency transformation of E. coli by high voltage electroporation, Nucl. Acids Res. 16, 6127-6145.

(4) Numata, K., Kikkawa, Y., Tsuge, T., Iwata, T., Doi, Y., and Abe, H. (2006) Adsorption of biopolyester depolymerase on silicon wafer and poly[(R)-3-hydroxybutyric acid] single crystal revealed by real-time AFM, Macromol. Biosci. 6, 41-50. 